\title{
The Challenge for Gene Therapy: Innate Immune Response to Adenoviruses
}

\author{
Bart Thaci, Ilya V. Ulasov, Derek A. Wainwright, and Maciej S. Lesniak \\ * The Brain Tumor Center, The University of Chicago Pritzker School of Medicine, 5841 South Maryland Ave, M/C 3026, \\ Chicago, IL 60637 \\ Correspondence to: Maciej S. Lesniak, email: mlesniak@surgery.bsd.uchicago.edu
}

Keywords: Adenovirus, interferon, interleukin-1, innate immune response

Received: January 25, 2011 Accepted: March 4, 2011, $\quad$ Aublished: March 5, 2011

Copyright: @ Thaci et al. This is an open-access article distributed under the terms of the Creative Commons Attribution License, which permits unrestricted use, distribution, and reproduction in any medium, provided the original author and source are credited.

ABSTRACT:

\begin{abstract}
Adenoviruses are the most commonly used vectors for gene therapy. Despite the promising safety profile demonstrated in clinical trials, the efficacy of using adenoviruses for gene therapy is poor. A major hurdle to adenoviral-mediated gene therapy is the innate immune system. Cell-mediated recognition of viruses via capsid components or nucleic acids has received significant attention, principally thought to be regulated by the toll-like receptors (TLRs). Antiviral innate immune responses are initiated by the infected cell, which activates the interferon (IFN) response to block viral replication, while simultaneously releasing chemokines to attract neutrophils, mononuclear- and natural killer-cells. While the IFN and cellular recruitment pathways are activated and regulated independently of each other, both are required to overcome immune escape mechanisms by adenoviruses. Recent work has shown that the generation of adenoviral vectors lacking specific transcriptionally-active regions decreases immune system activation and increases the chance for immune escape. In this review, we elucidate how adenoviral vector modifications alter the IFN and innate inflammatory pathway response and propose future targets with clinically-translational relevance.
\end{abstract}

\section{INTRODUCTION}

Adenoviruses are a continuously expanding class of at least 51 immunologically distinct serotypes [1] classified into 6 species (A-F) based on their hemagglutination properties, oncogenic potential, genotyping and phylogenetic analyses [2]. A small number of viral particles are sufficient to induce symptoms that will be determined by the adenovirus type and the inflammatory mediators [3]. In immunocompetent hosts, adenoviruses cause mild ocular, respiratory and gastrointestinal tract diseases. Thus, the safety profile for adenoviral administration into animals has been one of the reasons for their widespread use as gene therapy vectors. Although local injections have proven to be safe in clinical trials, intravascular delivery has been associated with one reported fatality [4]. An acute inflammatory response to the adenoviral vector was later determined to be the cause of the fatality. Therefore, investigating the complex interplay between adenoviruses and the immune system is of paramount importance for future safe and effective gene therapy.

\section{ADENOVIRUS BIOLOGY}

The adenovirus is a dsDNA non-enveloped virus of $70-90 \mathrm{~nm}$ in size (Figure 1A). Its core, a $36 \mathrm{kB}$ doublestranded linear DNA is packed within the icosahedral capsid [5]. The viral genome encodes several early (E1A, E1B, E2, E3 and E4) and late (L1-5) transcriptional units (Figure 1B) that give rise to multiple mRNAs and proteins via differential processing [6]. The capsid proteins are the primary antigens that define the various serotypes. Hexon- and penton-subunits form the icosahedral 'shell', while fiber protrusions help the virus to anchor to the cell surface.

\section{Adenoviral transduction}

Initial attachment of virion particles is mediated by the interaction of the fiber knob domain with the 
a)

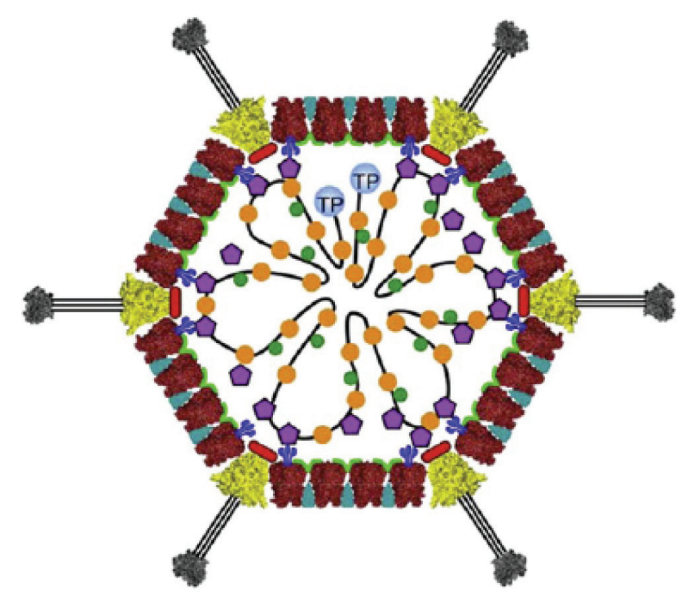

b)

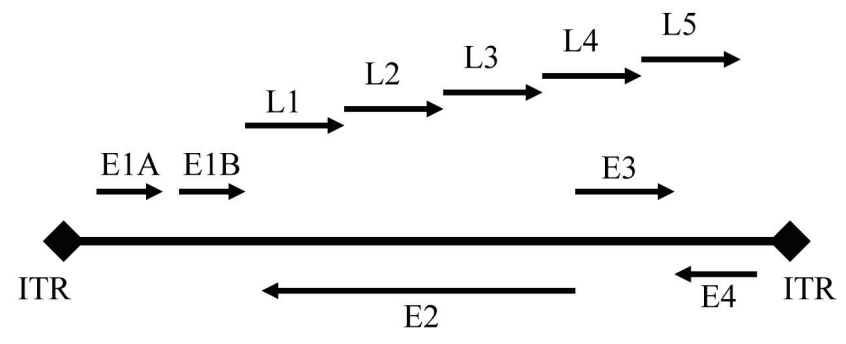

Figure 1: Adenovirus structure and transcription regions. A) Adenovirus capsid is composed of three major and four minor proteins. The three major proteins plus protein IX form the outer surface. Reproduced with permission [5] $B$ ) The double stranded DNA adenoviral linear genome is covalently linked at its ends to terminal proteins via inverted terminal repeats (ITRs). The first viral transcription unit to be expressed is E1A that activates the other early adenovirus transcripts (E1B, E2, E3 and E4). Late gene transcription (L1-L5) is activated after the onset of DNA replication and is under the control of major late promoter (MLP). Arrows indicate the direction of transcription.

effectors of IFN-AR and IL-1R diverge to block viral replication using different signal transduction pathways. While the IFN response acts in an autocrine/paracrine fashion to contain and destroy the virus from within the cell, the interleukin pathway recruits a pro-inflammatory infiltrate to eliminate the pathogen.

The quick nature of the inflammatory responses suggests that an early recognition of the virus activates an immature form of IL-1 which resides in the cytosol. But the maximum inflammatory response relies on a fullyfunctioning IL-1R $[12,14]$ and a number of protein kinases induced upon infection (Figure 1). These protein kinases, JNK, ERK1/2 and p38 MAPK, are also downstream effectors of non-specific stress response pathways [15].

The earliest sensor to be activated upon viral infection appears to be triggered by the adenoviral fiber binding with the CAR [16]. While the downstream signaling of CAR has yet to be elucidated, recent work has shown that CAR promotes the clustering of junctional adhesion molecule-like protein (JAML) and activation of phosphoinositide 3-kinase (P13K) [17]. Irrespective of the possible effectors involved [18], adenovirus binding to CAR induces downstream signaling of ERK1/2, JNK and MAPK, followed by NF- $\mathrm{KB}$ activation (Figure 2) and the up-regulation of chemokines.

Current dogma supports the hypothesis that the earliest event inducing innate immunity is the interaction of the RGD motif with $\alpha v$ integrins, especially B3 [12]. Furthermore, the downstream signaling of $\alpha \mathrm{v}$ integrins induces NF- $\mathrm{KB}$ activation and subsequently increases IL-1 expression, which has been reviewed elsewhere [19]. Importantly, the intensity of this response depends on endosomal viral escape and the presence of foreign 
DNA, since empty capsids do not induce transcription of chemokines [13].

Once internalized within host cells, adenoviral dsDNA can be sensed within the endosome via several TLRs [20] such as TLR9; in the cytosol by DNAdependent activator of IFN-regulatory factors (DAI) and/or nucleotide oligomerization domain (NOD)-like receptors (NLRs). Thus, the context of the immune response will depend on which of the pathways become activated. Downstream effectors of activated TLR9 diverge to activate both IFN- and inflammatory-responses. Accordingly, DAI relies on the I $\kappa$ B kinases, TBK1/IKKi, to induce the IFN response [21]. In contrast, NLRs bind with apoptosis speck protein (ASC) and caspases to form the 'inflammasome' [22], which cleaves the immature forms of pro-IL-1 and pro-IL-18 into their mature and active forms [23]. Subsequently, IL-1R activation leads to activation of NF- $\kappa B$ followed by the release of various chemokines (Table 1) [12, 16, 18, 24-29]. The broad effects of chemokines induced during adenoviral delivery have to be considered when designing gene therapy vectors. The resulting immune derangements, ranging from immunosuppression to autoimmunity, play a significant role in pathogenesis. The ability to decrease the level of inflammation [30] or enhance and modulate the immune response [31] with adenoviral vectors will increase the potential for immunotherapeutic success.

Table 1: Triggered innate inflammatory pathways.

\begin{tabular}{|c|c|c|}
\hline Chemokine & Triggered pathway & Reference \\
\hline IL-1 & The 'endogenous pyrogen', induces production of all the other cytokines & 12 \\
IL-18 & Enhances T and NK cell maturation, cytokine production and cytotoxicity & 25 \\
IL-8 & Polymorphonuclear leukocyte chemotaxis and activation & 26 \\
GRO- $\alpha, \gamma$ & Structurally and functionally similar to IL-8 & 16 \\
IL-6 & Secreted by monocytes and macrophages during adenovirus infection & 24 \\
CXCL1 & Induces neutrophil chemotaxis and respiratory burst activity & 27 \\
MCP-1 & Monocyte and T-lymphocyte chemotactic factor & 28 \\
RANTES & Chemotactic factor for NK cells & 29 \\
TNF- $\alpha$ & Triggers apoptosis or necrosis in infected cells & 18 \\
\hline
\end{tabular}

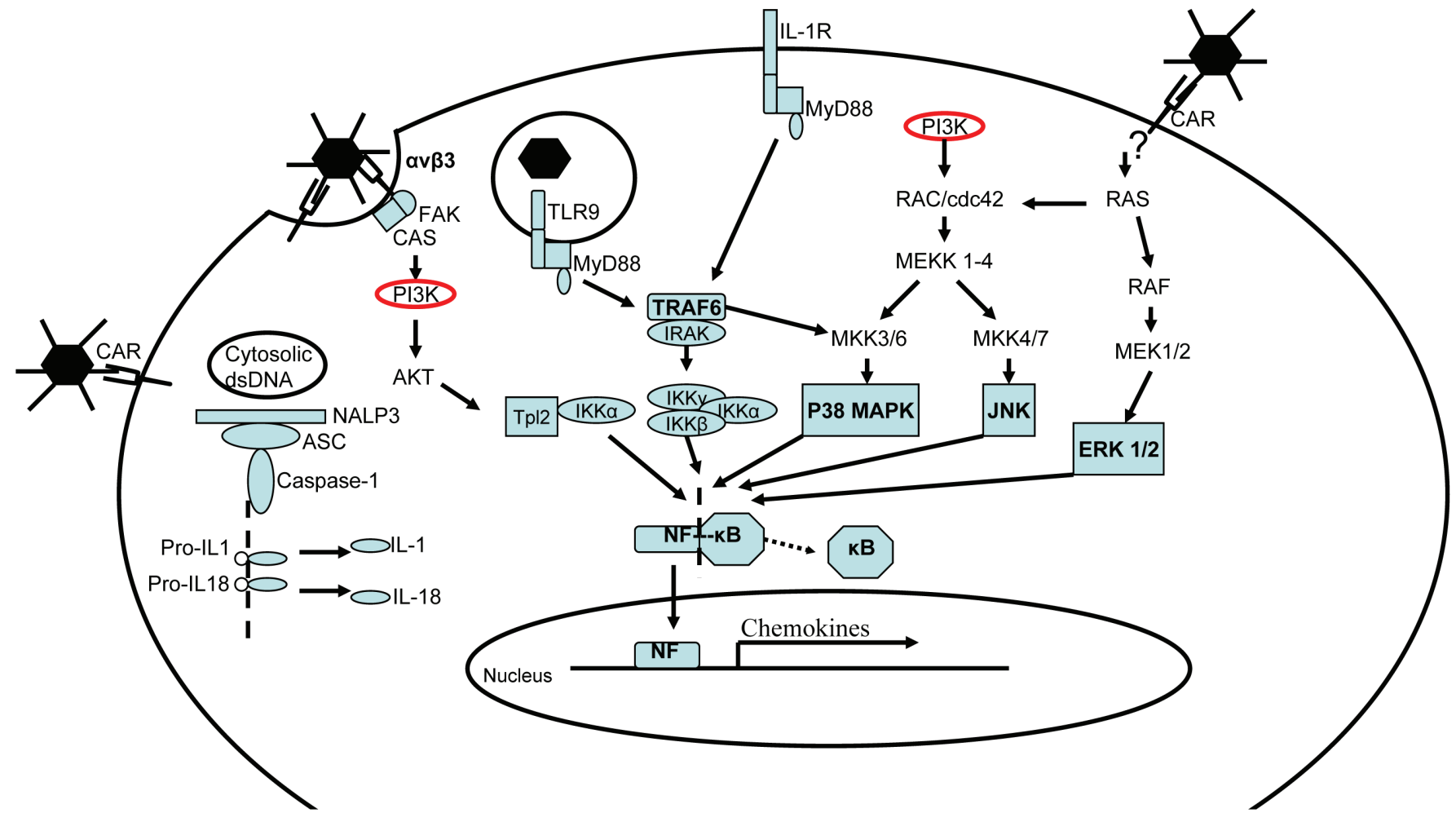

Figure 2: Inflammatory response to adenovirus infection. CAR or integrin binding to adenovirus triggers PI3K and MAPK kinases. NLRs activate IL-1/18 which act via IL-1R to induce IKK kinases, which are also induced by recognition of viral DNA in endosomes. After kinases release NF from NF- $\kappa \mathrm{B}$, it transfers to the nucleus to induce chemokine transcription. 


\section{INTERFERON/PARACRINE RESPONSE}

Three classes of IFNs have been identified according to the receptor through which they signal. Type I IFNs comprise 13 IFN- $\alpha$ subtypes, IFN- $\beta$, IFN- $\kappa$, IFN- $\varepsilon$, IFN-o, IFN- $\tau$ and IFN- $\delta$. All of the type I IFNs signal through IFN-AR. Thus, mice deficient for IFN-AR have an increased susceptibility to viral infections [32]. Type II IFNs are secreted by lymphocytes in response to different pathogens during the adaptive immune response, while type III IFNs are not well characterized [33]

Adenovirus-mediated IFN responses are induced, at least in part, by the recognition of foreign nucleic acid. Unlike the inflammatory responses, IFN has not been shown to be induced during adenoviral interaction with cell-surface receptors. Furthermore, the adenovirusinduced IFN response is cell specific [34]. While myeloid dendritic cells (mDCs) recognize adenoviral DNA in the cytoplasm, plasmacytoid DCs (pDCs) depend on TLR9, located in endosomes.

The discovery of the TLRs resulted in a new and focused investigative path for innate immunity [35, 36]. The mammalian TLR family consists of at least 11 members localized on the cell surface or inside endosomes. Important to adenoviral recognition, TLR9 localizes within endosomes and recognizes adenoviral CpG-rich DNA. In response to TLR9-activation, pDCs secrete IFN- $\alpha$ via the MyD88-dependent pathway [37]. The MyD88-dependent pathway is analogous to the IL-1R pathway: after stimulation, MyD88 recruits IL-1 receptor associated receptor kinase 1 (IRAK1) and TNF receptorassociated factor-6 (TRAF6). This complex activates MAP kinases and interferon regulatory factor 7 (IRF7). In pDCs, this pathway leads to the production of type I IFNs [38] (Figure 3), whereas in other types of DCs, such as mDCs, it leads to NF- $\mathrm{KB}$ activation and subsequent increased pro-inflammatory cytokine expression.

In mDCs, macrophages or fibroblasts, IFN production is not related to TLR recognition, nor dependent on the MyD88/TRIF pathway [37]. Rather, the presence of a cytosolic receptor, DAI, is activated and subsequently induces an IFN response upon foreign DNA recognition [21]. The downstream effectors of DAI are dependent on TBK1/IKKi and IRF3/7 for type 1 IFN induction. However, the recent generation of DAI-KO mice has contradicted previous data in the field, which demonstrates that DAI expression is not essential for the IFN response. Whether the MyD88/TRIF and DAI pathways are redundant in some cells, or other receptors exist, is currently unknown.

The aforementioned pathways that lead to the induction of IFN expression are not affected by adenovirus. Some viruses such as hepatitis $\mathrm{C}$ virus (HCV) or varicella-zoster virus (VZV) have been demonstrated to prolong viral replication in tissues by inhibiting type I IFN transcription $[39,40]$. In contrast, type I IFN expression

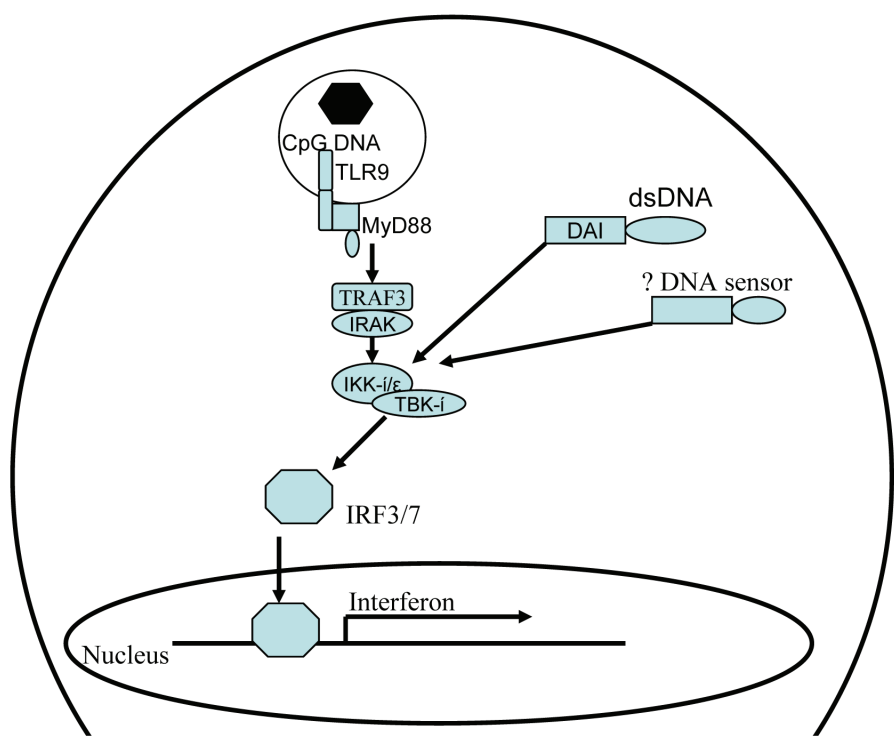

Figure 3: Interferon induction during adenovirus infection. In plasmacytoid DC adenoviral DNA activates TLR9 in plasmacytoid DCs, whereas DAI is activated in mDCs. The down-stream signaling converges in TBK1/IKKí activation and culminates in IRF3/7 transfer to the nucleus to induce IFN transcription.

is not affected by adenoviral infection. However, the downstream pathways of IFN expression are blocked. Regardless, once induced, IFN acts in a paracrine/ autocrine fashion to block adenoviral replication.

Type I IFNs bind to their cognate receptor which leads to the activation of JAK1/TYK2 kinases and is followed by the recruitment and phosphorylation of STATs. STAT1 and STAT2 associate with IRF9 to form ISGF3, which induces more than 300 IFN-stimulated genes (ISGs) [41]. The intensity of this response is drastically reduced during adenoviral infection, which inhibits the formation of ISGF3. As a result, only a few ISGs, such as Protein Kinase R (PKR) and Myxovirus resistance A protein (MxA) [42] have been shown to be activated upon adenoviral infection. PKR belongs to a family of protein kinases that respond to environmental stresses by phosphorylating E1F2 $\alpha$ to regulate protein synthesis. At the N-terminus of PKR, two RNA binding motifs exist that release the negative steric hindrance and allow dimerization of PKR on contact with RNA [43]. In contrast, MxA GTPases are involved in vesicle budding, organogenesis and cytokinesis. By virtue of their location near the endoplasmic reticulum, MxA can block viral replication at early time points by trapping essential viral proteins [44].

A complex interplay between the IFN and inflammatory responses is necessary to clear adenoviral infections. In bone marrow-derived macrophages, IRF3 activation and IFN induction have been shown to be influenced by inhibitors of the inflammatory pathway, such as JNK inhibitors [45]. Interaction of integrins with the adenoviral fiber RGD motif induces JNK to prime IRF3, whose full activation requires phosphorylation by TBK1. In addition, the recruitment of NK cells into the liver 
after intravenous injection of adenovirus is independent of the IFN response. However, the activation of NK cells requires IFN downstream signaling, since recruited NK cells in IFN- $\mathrm{R}^{-/-}$mice fail to control adenoviral infection [46].

Through evolution, adenoviruses have developed mechanisms to dampen and escape the immune response. These are more effective against ISGs than inflammatory mediators. Moreover, during adenoviral infections, inflammatory mediator levels such as IL-1 $\alpha$ increase 20fold, while IFN- $\alpha$ increases less than 2-fold [3]. However, genetic manipulation of adenovirus is independent of the IFN response. More importantly, generation of adenoviruses lacking specific innate immune systeminterfering genes has allowed the mechanistic study and determination of relevance for many genes required for innate immune system-mediated adenoviral clearance [47].

\section{Immune Response to Adenoviral Vectors}

Adenoviruses are the most commonly used gene therapy vectors. Due to the small size, the adenoviral capsid structure does not allow for extra DNA to be packaged properly. Thus, in order to insert a gene of interest into the adenoviral genome, a similar size of viral DNA must be removed. Furthermore, the viral cytopathic effect has to be minimized. The first generation E1-deleted adenoviral vectors were less cytopathic but induced innate immune responses very quickly [28, 48]. To decrease overall immune activation, vectors were deleted of more dispensable transcriptional regions. Three generations of vectors were created. Of those, 'gutless' vectors, deleted for the entire adenoviral genome, had the least antigenic and immunostimulatory properties.

Adenoviral vectors deficient of early transcript regions showed a different sensitivity towards IFN and inflammatory responses. Deletion of the $\mathrm{E} 1$ region reduced the IFN resistance more than deleting E4. Furthermore, vectors lacking E3 genes were more vulnerable to inducing the inflammatory response. It should be noted that the E2 transcripts have not been shown to block the innate immune response. Rather, E2 gene transcripts boost the immune response [49].

Deletion of E1A has been shown to be very important for inhibiting the immune response. The products of E1A, 289R and 243R, named after their amino acid residue length, not only bind to cell cycle regulatory proteins such as $\mathrm{pRB}$, but also have transcriptional activator/repressor properties. It is clear that E1A can rescue other viruses from the IFN response by inhibiting the formation of the ISGF3 complex [50, 51]. For example, E1A inhibits transcription of JAK1 in epithelial cells [42]. In contrast, the $\mathrm{E} 1 \mathrm{~B}$ region encodes three major proteins that are 55$\mathrm{kDa}, 19-\mathrm{kDa}$ and $17-\mathrm{kDa}$ in size. The components of E1B, complexed with the E4-ORF6, block host mRNA transport and p53 transcriptional activity while facilitating late viral mRNA expression. Furthermore, the E1B-19$\mathrm{kDa}$ component is a BCL2 homologue and acts as a potent inhibitor of apoptosis.

Adenoviral transduction of cells results in the transcription of both host and viral DNA, resulting in a greater amount of total DNA within a cell, which can trigger host cell defenses. However, the adenovirus has selectively evolved to deal with those cell defenses. E4 proteins hijack the machinery associated with the DNA damage pathways [52]. There are six E4 proteins produced through differential splicing of the open reading frame (ORF). The E4ORF3 and E4ORF6 show functional redundancy. Both form complexes with the E1B-55kDa component and regulate late adenoviral gene expression.

Inflammatory responses induced by adenoviral transduction are also counteracted by the E3 region transcripts. Inserting the E3 region in recombinant vectors decreases the maximal innate immune response, which consequently permits long term adenoviral gene expression [53]. The E3-14.7 kDa component inhibits the NF- $\kappa \mathrm{B}$-induced transcription of inflammatory mediator expression [54], while the E3-10.4kDa/14.5kDa components inhibits TNF $\alpha$ and FAS ligand-induced cell death by internalizing receptor internalization and degradation alpha/beta $(\mathrm{RID} \alpha / \beta)$ receptors [55]. The E3$19 \mathrm{kDa}$ glycoprotein inhibits peptide presentation by $\mathrm{MHC}$ class I via a specific motif at the carboxy terminus, which retargets $\mathrm{MHC}$ class I to the endoplasmic reticulum [56].

The functional relevance of adenoviral protein interference with innate immunity must be carefully understood if an effective therapy can be produced. For gene therapy, which requires the prolonged expression of therapeutic genes by a transduced cell, maintenance of cell viability and the reduction of inflammation is required. The E3-14.7kDa component inhibits the NF- $\kappa \mathrm{B}$-induced transcription of inflammatory mediator expression [54], while the E3-10.4kDa/14.5kDa component inhibits $\mathrm{TNF} \alpha$ and FAS ligand-induced cell death by receptor internalization and degradation of alpha/beta $(\mathrm{RID} \alpha / \beta)$ receptors [55]. In addition, inflammation can be further reduced by immunosuppressive drugs, such as cyclophosphamide, which have been shown to enhance the effectiveness of adenoviral vectors in different species in non-toxic doses [58, 59].

The overall intensity of the systemic immune response will depend on the level of induced inflammatory mediators by the infected cell. Fiber modifications have expanded the spectrum of cells that adenoviruses can infect, which consequently increases the risk of adverse effects, especially when injected systemically. However, intravascular delivery of gene vectors is required for effectively treating metastatic disease or the transduction of large number of cells in vivo. 


\section{Intravascular delivery}

Irrespective of the fiber modifications, adenoviruses are sequestered by liver cells after intravascular injection [60]. When the liver is not the direct target, intravascular delivery of naked virus has been associated with adverse side-effects and limited efficacy. However, the discovery of coagulation factor binding properties of virions and differences between adenoviral groups has elucidated the mechanism to avoid for liver detargeting [61, 62]. Of the different strategies used to limit the toxicity of adenoviral vectors during systemic administration, only a handful have been beneficial including surface modifications, genetic deletion and use of cell carriers.

Surface modifications have been of great interest not only for intravascular delivery but also for improving cell transduction since wild-type adenovirus fibers cannot transduce target cells lacking CAR. However, fiber modifications alone [24] have not proven to limit the binding with coagulation factors, such as FX or FIX. Structural and mutagenesis studies have shown Ad5 hexon hypervariable regions (HVR) 5 and 7 to be critical for this interaction [63]. To prevent this interaction, genetic modifications, hexon serotype substitution and PEG-masking are useful approaches with proven success, while maintaining efficacy. By genetically inserting a large amino acid biotin acceptor peptide (BAP) into HVR5, affinity to FX factor was reduced 10,000-fold. This allowed a 10-fold increase in the maximum tolerated dose [64]. Substitution of Ad5 hexon with serotype 3 had very similar effects [65]. Thus, hexon modifications promote immune escape, which is critical to successful therapy since most patients already possess circulating antibodies to Ad5 hexon [66].

Polyethylene glycol (PEG) is a linear synthetic polymer that can be synthesized to varying lengths, from 200-40,000D. Its properties include low toxicity, low immunogenicity and hydrophilicity, making it a very attractive compound for modifications of various peptides or proteins. This has also proven true for adenovirus PEGylation [67]. The PEG 20kDa length has proven to be most effective $[68,69]$. Decreased activation of the immune response and reduced IL-6 expression was inversely correlated with the PEGylation rate when compared to native Ad5 [70, 71].

Hepatic detargeting can also be achieved using cells as vehicles for adenovirus delivery, instead of 'naked' adenovirus [72]. Our lab has shown that the inflammatory response is reduced by using mesenchymal stem cells loaded with adenoviruses [73]. These immunosuppressive properties can therefore be harnessed to achieve longterm transgene expression. Also, stem cells loaded with adenoviral vectors have shown to be attracted to growth factors or chemokines and can target specific niches even when injected systemically [74].

Our rationale for investigating and exploring the adenovirus for gene therapy is to further increase the efficacy for potential clinical use in glioblastoma patients. One such way to do this is by using a surface modification combining PEGylation with liposome encapsulation of the adenovirus [75]. This has been performed with success using systemically-delivered PEGylated adenovirus with tumor cell-specific promoters to control metastasis [69]. However, as we investigate new mutated or aberrantly expressed tumor promoters, more effective adenoviral vectors will be constructed.

\section{CONCLUSIONS}

The innate immune response to adenoviral vectors will always interfere with gene therapy in some way. During each step of viral delivery there is a barrier to overcome. Many different sensors exist for adenoviral replication starting from the initial attachment to the cell surface via the CAR and integrins, later in endosomes via TLRs, in the cytoplasm and even in the nucleus. Modifications have made adenoviral vectors even more sensitive to innate immune responses. Understanding these different pathways and how to modulate them will bring us closer to clinical use. Cell specificity appears to be a major limitation in predicting human innate immune responses. The unpredictable adverse effects encountered during intravascular therapy should not make us bitter about the potentials of adenoviral vectors. Experience with 'gutless' vectors has proven that less is more, even in medicine.

\section{ACKNOWLEDGMENT}

This work was supported by the NCI (R01CA122930, R01CA138587), the National Institute of Neurological Disorders and Stroke (U01NS069997), and the American Cancer Society (RSG-07-276-01-MGO).

\section{REFERENCE}

1. Ebner K, Rauch M, Preuner S, Lion T. Typing of human adenoviruses in specimens from immunosuppressed patients by PCR-fragment length analysis and real-time quantitative PCR. J Clin Microbiol 2006; 44: 2808-15.

2. Madisch I, Harste G, Pommer H, Heim A. Phylogenetic analysis of the main neutralization and hemagglutination determinants of all human adenovirus prototypes as a basis for molecular classification and taxonomy. J Virol 2005; 79: 15265-76.

3. Moro MR, Bonville CA, Suryadevara M, Cummings E, Faddoul D, Kobayaa H, Branigan PJ, Domachowske JB. Clinical features, adenovirus types, and local production of inflammatory mediators in adenovirus infections. Pediatr Infect Dis J 2009; 28: 376-80.

4. Raper SE, Chirmule N, Lee FS, Wivel NA, Bagg A, Gao 
GP, Wilson JM, Batshaw ML. Fatal systemic inflammatory response syndrome in a ornithine transcarbamylase deficient patient following adenoviral gene transfer. Mol Genet Metab 2003; 80: 148-58.

5. Nemerow GR, Pache L, Reddy V, Stewart PL. Insights into adenovirus host cell interactions from structural studies. Virology 2009; 384: 380-8.

6. McConnell MJ, Imperiale MJ. Biology of adenovirus and its use as a vector for gene therapy. Hum Gene Ther 2004; 15: 1022-33.

7. Bergelson JM, Cunningham JA, Droguett G, Kurt-Jones EA, Krithivas A, Hong JS, Horwitz MS, Crowell RL, Finberg RW. Isolation of a common receptor for Coxsackie B viruses and adenoviruses 2 and 5. Science 1997; 275: 1320-3.

8. Gaggar A, Shayakhmetov DM, Lieber A. CD46 is a cellular receptor for group B adenoviruses. Nat Med 2003; 9: 140812.

9. Wickham TJ, Mathias P, Cheresh DA, Nemerow GR. Integrins alpha $\mathrm{v}$ beta 3 and alpha $\mathrm{v}$ beta 5 promote adenovirus internalization but not virus attachment. Cell 1993; 73: 309-19.

10. Trotman LC, Mosberger N, Fornerod M, Stidwill RP, Greber UF. Import of adenovirus DNA involves the nuclear pore complex receptor CAN/Nup214 and histone H1. Nat Cell Biol 2001; 3: 1092-100.

11. Suomalainen M, Nakano MY, Keller S, Boucke K, Stidwill RP, Greber UF. Microtubule-dependent plus- and minus end-directed motilities are competing processes for nuclear targeting of adenovirus. J Cell Biol 1999; 144: 657-72.

12. Di Paolo NC, Miao EA, Iwakura Y, Murali-Krishna K, Aderem A, Flavell RA, Papayannopoulou T, Shayakhmetov DM. Virus binding to a plasma membrane receptor triggers interleukin-1 alpha-mediated proinflammatory macrophage response in vivo. Immunity 2009; 31: 110-21.

13. Muruve DA, Petrilli V, Zaiss AK, White LR, Clark SA, Ross PJ, Parks RJ, Tschopp J. The inflammasome recognizes cytosolic microbial and host DNA and triggers an innate immune response. Nature 2008; 452: 103-7.

14. Shayakhmetov DM, Li ZY, Ni S, Lieber A. Interference with the IL-1-signaling pathway improves the toxicity profile of systemically applied adenovirus vectors. J Immunol 2005; 174: 7310-9.

15. Gehart H, Kumpf S, Ittner A, Ricci R. MAPK signalling in cellular metabolism: stress or wellness? EMBO Rep; 11: 834-40.

16. Tamanini A, Nicolis E, Bonizzato A, Bezzerri V, Melotti P, Assael BM, Cabrini G. Interaction of adenovirus type 5 fiber with the coxsackievirus and adenovirus receptor activates inflammatory response in human respiratory cells. J Virol 2006; 80: 11241-54.

17. Verdino P, Witherden DA, Havran WL, Wilson IA. The molecular interaction of CAR and JAML recruits the central cell signal transducer PI3K. Science 2010; 329:
1210-4.

18. Philpott NJ, Nociari M, Elkon KB, Falck-Pedersen E. Adenovirus-induced maturation of dendritic cells through a PI3 kinase-mediated TNF-alpha induction pathway. Proc Natl Acad Sci U S A 2004; 101: 6200-5.

19. Liu Q, Muruve DA. Molecular basis of the inflammatory response to adenovirus vectors. Gene Ther 2003; 10: 93540.

20. Uematsu S, Akira S. Toll-like receptors and Type I interferons. J Biol Chem 2007; 282: 15319-23.

21. Takaoka A, Wang Z, Choi MK, Yanai H, Negishi H, Ban T, Lu Y, Miyagishi M, Kodama T, Honda K, Ohba Y, Taniguchi T. DAI (DLM-1/ZBP1) is a cytosolic DNA sensor and an activator of innate immune response. Nature 2007; 448: 501-5.

22. Martinon F, Burns K, Tschopp J. The inflammasome: a molecular platform triggering activation of inflammatory caspases and processing of proIL-beta. Mol Cell 2002; 10 : 417-26.

23. Dinarello CA. Interleukin-1 beta, interleukin-18, and the interleukin-1 beta converting enzyme. Ann N Y Acad Sci 1998; 856: 1-11.

24. Koizumi N, Yamaguchi T, Kawabata K, Sakurai F, Sasaki T, Watanabe Y, Hayakawa T, Mizuguchi H. Fiber-modified adenovirus vectors decrease liver toxicity through reduced IL-6 production. J Immunol 2007; 178: 1767-73.

25. Xing Z, Zganiacz A, Wang J, Divangahi M, Nawaz F. IL12-independent Th1-type immune responses to respiratory viral infection: requirement of IL-18 for IFN-gamma release in the lung but not for the differentiation of viralreactive Th1-type lymphocytes. J Immunol 2000; 164: 2575-84.

26. Alcorn MJ, Booth JL, Coggeshall KM, Metcalf JP. Adenovirus type 7 induces interleukin- 8 production via activation of extracellular regulated kinase $1 / 2$. J Virol 2001; 75: 6450-9.

27. Chintakuntlawar AV, Chodosh J. Chemokine CXCL1/ $\mathrm{KC}$ and its receptor CXCR2 are responsible for neutrophil chemotaxis in adenoviral keratitis. J Interferon Cytokine Res 2009; 29: 657-66.

28. Muruve DA, Barnes MJ, Stillman IE, Libermann TA. Adenoviral gene therapy leads to rapid induction of multiple chemokines and acute neutrophil-dependent hepatic injury in vivo. Hum Gene Ther 1999; 10: 965-76.

29. Zaiss AK, Liu Q, Bowen GP, Wong NC, Bartlett JS, Muruve DA. Differential activation of innate immune responses by adenovirus and adeno-associated virus vectors. J Virol 2002; 76: 4580-90.

30. Tang Y, Reay DP, Salay MN, Mi MY, Clemens PR, Guttridge DC, Robbins PD, Huard J, Wang B. Inhibition of the IKK/NF-kappaB pathway by AAV gene transfer improves muscle regeneration in older $\mathrm{mdx}$ mice. Gene Ther 2010.

31. Yuan X, Hu J, Belladonna ML, Black KL, Yu JS. 
Interleukin-23-expressing bone marrow-derived neural stem-like cells exhibit antitumor activity against intracranial glioma. Cancer Res 2006; 66: 2630-8.

32. Muller U, Steinhoff U, Reis LF, Hemmi S, Pavlovic J, Zinkernagel RM, Aguet M. Functional role of type I and type II interferons in antiviral defense. Science 1994; 264 : 1918-21.

33. Levraud JP, Boudinot P, Colin I, Benmansour A, Peyrieras $\mathrm{N}$, Herbomel P, Lutfalla G. Identification of the zebrafish IFN receptor: implications for the origin of the vertebrate IFN system. J Immunol 2007; 178: 4385-94.

34. Ishii KJ, Coban C, Kato H, Takahashi K, Torii Y, Takeshita F, Ludwig H, Sutter G, Suzuki K, Hemmi H, Sato S, Yamamoto M, Uematsu S, Kawai T, Takeuchi O, Akira S. A Toll-like receptor-independent antiviral response induced by double-stranded B-form DNA. Nat Immunol 2006; 7: 40-8.

35. Medzhitov R, Preston-Hurlburt P, Janeway CA, Jr. A human homologue of the Drosophila Toll protein signals activation of adaptive immunity. Nature 1997; 388: 394-7.

36. Takeda K, Akira S. Toll-like receptors in innate immunity. Int Immunol 2005; 17: 1-14.

37. Zhu J, Huang $\mathrm{X}$, Yang $\mathrm{Y}$. Innate immune response to adenoviral vectors is mediated by both Toll-like receptordependent and -independent pathways. J Virol 2007; 81: 3170-80.

38. Hoshino K, Sugiyama T, Matsumoto M, Tanaka T, Saito M, Hemmi H, Ohara O, Akira S, Kaisho T. IkappaB kinasealpha is critical for interferon-alpha production induced by Toll-like receptors 7 and 9. Nature 2006; 440: 949-53.

39. Foy E, Li K, Sumpter R, Jr., Loo YM, Johnson CL, Wang C, Fish PM, Yoneyama M, Fujita T, Lemon SM, Gale M, Jr. Control of antiviral defenses through hepatitis $C$ virus disruption of retinoic acid-inducible gene-I signaling. Proc Natl Acad Sci U S A 2005; 102: 2986-91.

40. Sen N, Sommer M, Che X, White K, Ruyechan WT, Arvin AM. Varicella-zoster virus immediate-early protein 62 blocks interferon regulatory factor 3 (IRF3) phosphorylation at key serine residues: a novel mechanism of IRF3 inhibition among herpesviruses. J Virol 2010; 84: 9240-53.

41. Sadler AJ, Williams BR. Interferon-inducible antiviral effectors. Nat Rev Immunol 2008; 8: 559-68.

42. Shi L, Ramaswamy M, Manzel LJ, Look DC. Inhibition of Jak1-dependent signal transduction in airway epithelial cells infected with adenovirus. Am J Respir Cell Mol Biol 2007; 37: 720-8.

43. Kitajewski J, Schneider RJ, Safer B, Munemitsu SM, Samuel CE, Thimmappaya B, Shenk T. Adenovirus VAI RNA antagonizes the antiviral action of interferon by preventing activation of the interferon-induced eIF-2 alpha kinase. Cell 1986; 45: 195-200.

44. Kochs G, Haller O. Interferon-induced human MxA GTPase blocks nuclear import of Thogoto virus nucleocapsids. Proc
Natl Acad Sci U S A 1999; 96: 2082-6.

45. Nociari M, Ocheretina O, Murphy M, Falck-Pedersen E. Adenovirus induction of IRF3 occurs through a binary trigger targeting Jun $\mathrm{N}$-terminal kinase and TBK1 kinase cascades and type I interferon autocrine signaling. J Virol 2009; 83: 4081-91.

46. Zhu J, Huang X, Yang Y. A critical role for type I IFNdependent NK cell activation in innate immune elimination of adenoviral vectors in vivo. Mol Ther 2008; 16: 1300-7.

47. Schaack J. Induction and inhibition of innate inflammatory responses by adenovirus early region proteins. Viral Immunol 2005; 18: 79-88.

48. Yang Y, Nunes FA, Berencsi K, Furth EE, Gonczol E, Wilson JM. Cellular immunity to viral antigens limits E1deleted adenoviruses for gene therapy. Proc Natl Acad Sci U S A 1994; 91: 4407-11.

49. Engelhardt JF, Ye X, Doranz B, Wilson JM. Ablation of E2A in recombinant adenoviruses improves transgene persistence and decreases inflammatory response in mouse liver. Proc Natl Acad Sci U S A 1994; 91: 6196-200.

50. Anderson KP, Fennie EH. Adenovirus early region 1A modulation of interferon antiviral activity. J Virol 1987; 61: 787-95.

51. Kalvakolanu DV, Bandyopadhyay SK, Harter ML, Sen GC. Inhibition of interferon-inducible gene expression by adenovirus E1A proteins: block in transcriptional complex formation. Proc Natl Acad Sci U S A 1991; 88: 7459-63.

52. Weitzman MD, Ornelles DA. Inactivating intracellular antiviral responses during adenovirus infection. Oncogene 2005; 24: 7686-96.

53. Ilan Y, Droguett G, Chowdhury NR, Li Y, Sengupta K, Thummala NR, Davidson A, Chowdhury JR, Horwitz MS. Insertion of the adenoviral E3 region into a recombinant viral vector prevents antiviral humoral and cellular immune responses and permits long-term gene expression. Proc Natl Acad Sci U S A 1997; 94: 2587-92.

54. Carmody RJ, Maguschak K, Chen YH. A novel mechanism of nuclear factor-kappaB regulation by adenoviral protein 14.7K. Immunology 2006; 117: 188-95.

55. Tollefson AE, Hermiston TW, Lichtenstein DL, Colle CF, Tripp RA, Dimitrov T, Toth K, Wells CE, Doherty PC, Wold WS. Forced degradation of Fas inhibits apoptosis in adenovirus-infected cells. Nature 1998; 392: 726-30.

56. Jackson MR, Nilsson $\mathrm{T}$, Peterson PA. Retrieval of transmembrane proteins to the endoplasmic reticulum. J Cell Biol 1993; 121: 317-33.

57. Herrmann $\mathrm{CH}$, Mathews $\mathrm{MB}$. The adenovirus E1B 19-kilodalton protein stimulates gene expression by increasing DNA levels. Mol Cell Biol 1989; 9: 5412-23.

58. Thomas MA, Spencer JF, Toth K, Sagartz JE, Phillips NJ, Wold WS. Immunosuppression enhances oncolytic adenovirus replication and antitumor efficacy in the Syrian hamster model. Mol Ther 2008; 16: 1665-73.

59. Kuriyama S, Tominaga K, Kikukawa M, Tsujimoto T, 
Nakatani T, Tsujinoue H, Okuda H, Nagao S, Mitoro A, Yoshiji H, Fukui H. Transient cyclophosphamide treatment before intraportal readministration of an adenoviral vector can induce re-expression of the original gene construct in rat liver. Gene Ther 1999; 6: 749-57.

60. Alemany R, Curiel DT. CAR-binding ablation does not change biodistribution and toxicity of adenoviral vectors. Gene Ther 2001; 8: 1347-53.

61. Shayakhmetov DM, Gaggar A, Ni S, Li ZY, Lieber A. Adenovirus binding to blood factors results in liver cell infection and hepatotoxicity. J Virol 2005; 79: 7478-91.

62. Waddington SN, McVey JH, Bhella D, Parker AL, Barker K, Atoda H, Pink R, Buckley SM, Greig JA, Denby L, Custers J, Morita T, Francischetti IM, Monteiro RQ, Barouch DH, van Rooijen N, Napoli C, Havenga MJ, Nicklin SA, Baker AH. Adenovirus serotype 5 hexon mediates liver gene transfer. Cell 2008; 132: 397-409.

63. Alba R, Bradshaw AC, Parker AL, Bhella D, Waddington SN, Nicklin SA, van Rooijen N, Custers J, Goudsmit J, Barouch DH, McVey JH, Baker AH. Identification of coagulation factor $(\mathrm{F}) \mathrm{X}$ binding sites on the adenovirus serotype 5 hexon: effect of mutagenesis on FX interactions and gene transfer. Blood 2009; 114: 965-71.

64. Shashkova EV, May SM, Doronin K, Barry MA. Expanded anticancer therapeutic window of hexon-modified oncolytic adenovirus. Mol Ther 2009; 17: 2121-30.

65. Short JJ, Rivera AA, Wu H, Walter MR, Yamamoto M, Mathis JM, Curiel DT. Substitution of adenovirus serotype 3 hexon onto a serotype 5 oncolytic adenovirus reduces factor $\mathrm{X}$ binding, decreases liver tropism, and improves antitumor efficacy. Mol Cancer Ther 2010; 9: 2536-44.

66. Abe S, Okuda K, Ura T, Kondo A, Yoshida A, Yoshizaki S, Mizuguchi H, Klinman D, Shimada M. Adenovirus type 5 with modified hexons induces robust transgene-specific immune responses in mice with pre-existing immunity against adenovirus type 5. J Gene Med 2009; 11: 570-9.

67. Kreppel F, Kochanek S. Modification of adenovirus gene transfer vectors with synthetic polymers: a scientific review and technical guide. Mol Ther 2008; 16: 16-29.

68. Doronin K, Shashkova EV, May SM, Hofherr SE, Barry MA. Chemical modification with high molecular weight polyethylene glycol reduces transduction of hepatocytes and increases efficacy of intravenously delivered oncolytic adenovirus. Hum Gene Ther 2009; 20: 975-88.

69. Yao X, Yoshioka Y, Morishige T, Eto Y, Watanabe H, Okada Y, Mizuguchi H, Mukai Y, Okada N, Nakagawa S. Systemic administration of a PEGylated adenovirus vector with a cancer-specific promoter is effective in a mouse model of metastasis. Gene Ther 2009; 16: 1395-404.

70. Eto Y, Yoshioka Y, Ishida T, Yao X, Morishige T, Narimatsu S, Mizuguchi H, Mukai Y, Okada N, Kiwada $\mathrm{H}$, Nakagawa S. Optimized PEGylated adenovirus vector reduces the anti-vector humoral immune response against adenovirus and induces a therapeutic effect against metastatic lung cancer. Biol Pharm Bull 2010; 33: 1540-4.

71. Mok H, Palmer DJ, Ng P, Barry MA. Evaluation of polyethylene glycol modification of first-generation and helper-dependent adenoviral vectors to reduce innate immune responses. Mol Ther 2005; 11: 66-79.

72. Ferguson SD, Ahmed AU, Thaci B, Mercer RW, Lesniak MS. Crossing the boundaries: stem cells and gene therapy. Discov Med 2010; 9: 192-6.

73. Ahmed AU, Rolle CE, Tyler MA, Han Y, Sengupta S, Wainwright DA, Balyasnikova IV, Ulasov IV, Lesniak MS. Bone Marrow Mesenchymal Stem Cells Loaded With an Oncolytic Adenovirus Suppress the Anti-adenoviral Immune Response in the Cotton Rat Model. Mol Ther 2010; 18: 1846-1856.

74. Danks MK, Yoon KJ, Bush RA, Remack JS, Wierdl M, Tsurkan L, Kim SU, Garcia E, Metz MZ, Najbauer J, Potter PM, Aboody KS. Tumor-targeted enzyme/prodrug therapy mediates long-term disease-free survival of mice bearing disseminated neuroblastoma. Cancer Res 2007; 67: 22-5.

75. Lanciotti J, Song A, Doukas J, Sosnowski B, Pierce G, Gregory R, Wadsworth S, O'Riordan C. Targeting adenoviral vectors using heterofunctional polyethylene glycol FGF2 conjugates. Mol Ther 2003; 8: 99-107. 